\title{
Language Contact in the Arab World: Realities and Implications
}

\author{
Ikram YOUCEF \\ Oran 2 University \\ Algeria
}

\begin{abstract}
The Arab world exhibits a fascinating linguistic case that is worth investigating. Likewise Algeria Arab speaking countries implement the policy of Arabization in order to preserve the image of Arabic from any type of threat. Hence, colonialism had not expired without an impact; Linguistic diversity is by far the outcome. The present paper aims at shedding light on the sociolinguistic phenomena such as: Diglossia, bilingualism, and borrowing with reference to the situation of the Arabic language. It tries to raise the question of the utility of the Quran's language in correspondence to our globalized era
\end{abstract}

Keywords: language policy, Arabization, linguistic diversity, Diglossia, bilingualism, globalized era.

\section{Introduction}

It is widely acknowledged that language is the key of human communication being spoken or written. On sociolinguistic grounds, the language can only be recognized according to the degree of its use amongst the members of the community. Arabic, for instance, is a Semitic language whose status portrays a safeguard for Arab people in order to protect their identity however, the post-colonial era is relatively coming with the line of globalization which progressively has led to another type of linguistic hegemony.

\section{Language Contact: Diglossia as a Key Concept}

The term Diglossia is a sociolinguistic phenomenon that gained wider currency in 1959 by the influential Charles Fergusson who suggests an elaborative framework that identifies four speech communities mainly, the Arabic speaking world (Arabic is a first language), Haiti, German speaking Switzerland and Greece. In a sense Fergusson sheds light on two varieties of the same language, each serving definite functions in a given society. The former variety is referred to as High, respectively $(\mathrm{H})$ whereas the latter is a Low variety or simply $(\mathrm{L})$. He maintains that the high variety tends to be a prestigious one, basically reserved to standard and formal usage and mostly appearing on a written mode. On the other hand, the L variety is spoken; it is generally referred to as 'the dialect'. (Fergusson, 1959, p.329) distinguishes some cases where the two varieties are used as shown below: (some other cases are not cited)

\begin{tabular}{|l|l|}
\hline High Variety & Low Variety \\
\hline Sermon in church or Mosque & Instructions to servants, waiters, workmen and \\
Speech in parliament & clerks \\
Personal letters & Family/ friends conversations \\
University lectures & Folk literature \\
Poetry & Political cartoons \\
\hline
\end{tabular}

\subsection{Ferguson's Classification of High and Low Varieties Uses.}

It is worth noting that, Diglossia was initially introduced by William (Marçais, 1930) ${ }^{\mathbf{1}}$ as a descriptive analysis of the language situation in the Arab world, particularly, Algeria. He posits that there exists a competition between two varieties of genetically related languages, one is spoken, and the other is indeed written. (Fergusson, 1959) affirms that the phenomenon of Diglossia is also characterized by certain complications as far as the Arab world is concerned. In some cases, there exist two languages in a society. This was conceptualized by (Fishman, 1967) who acknowledges the existence of two distinct unrelated languages in a given context, each of which serving as both (H) and (L).

\footnotetext{
1،La concurrence entre une langue savante écrite et une langue vulgaire, parfois exclusivement parlée. ‘’ Marçais (1930:402)
} 
Fishman introduces the concept of 'Extended Diglossia' which is totally different from the aforementioned Fergusson' 'classical Diglossia'. He further puts forwards illustrative cases such as: textual Hebrew, Yiddish, Standard English in addition to Spanish Creole and Guarani in Paraguay.

\subsection{Diglossia in the Arab World}

As far as the case of Arabic is concerned, (Fergusson, 1959) identifies the co-existence of two varieties that are genetically related. The high variety represents classical Arabic (CA) or Modern Standard Arabic (MSA) Fuṣ̣á meanwhile, the Low variety represents the colloquial/dialectal variety. (Kaye, 2002) confirms that Arabic is one of the most complicated Diglossic situations in the world. Standard Arabic (SA) or (MSA) is the widely recognized language by Arab people despite the existence of a considerable number of varieties; SA remains the sole official language in the region. Yet, Fuṣhá is "no body's mother tongue" as cited by (Maamouri, 1998.p33) In Algeria, SA is considered as both national and official language of the country. It is undoubtedly regraded as a bond of culture and identity especially by the Pan- Arabism (Palmer, 2008)

In an attempt, the current linguistic situation of the Arab world represents a scenery of two basic varieties of the same language, Arabic, which is the official language of the majority of Arab countries today, encompasses the existence of the two aforementioned varieties, respectively, CA the high variety restricted to both prestigious and sophisticated usage in addition to colloquial Arabic. Historically speaking, CA is the language of Quran and Hadith revelation by the prophet Mohammed (peace be upon him). It is clear that, CA stands at the core of Arabic language purity and correctness due to its valuable grammar structures and lexicon. Language is said to be compelled to serve human communication. So, Arabic by virtue enshrines all what goes hand in hand with culture and identity.

The present situation in the Arab world however is problematic since CA and CoA do not share the same characteristics. Arab speakers rely on the spoken variety to communicate. As a means of clarification, CoA is only acquired unlike CA that is learnt in formal circumstances. This controversy has led a number of scholars to reconsider the basic usefulness of CA as opposed to CoA, the status of both is influenced by language planning policies or even results from the phenomenon of 'multilingualism' which is nowadays spread worldwide.

\section{Forms of the Arabic Language}

3.1. Classical Arabic (CA) is a standard variety of the Arabic language that can be traced back to the $6^{\text {th }}$ and $7^{\text {th }}$ CCE. It is therefore originated from a spoken dialect in pre-Islamic Mecca. At that time, it was exclusively a lingua Franca in the whole Arabian Peninsula. Hence, CA enjoys a higher degree of 'sacredness' (Zughoul, 1985, p.203) since it is the language of the holy book of Quran and Hadith as well. CA reflects a huge bulk of authentic literature and poetry especially, the one related to the pre-Islamic era. In Overall, in spite of the complexity of its linguistic system, it symbolizes a unique content in terms of morphology, phonology and lexicon. What makes CA distinct is mainly 'inflections' or 'I'rāb'. CA is utilized in prestigious and formal contexts unlike everyday interactions which are done by dialectal Arabic.

3.2. Modern Standard Arabic (MSA) it has been widely spread throughout the Arab world as a simplified version of CA. While classical Arabic is well viewed as the richest literary form of Arabic, MSA fits better the language of press, education and all sorts of written publications. MSA embodies similar features with CA more precisely at the lexical and syntactic levels. In Algeria, MSA is taught at schools starting from the primary level. As for the difference between both varieties, one might add that CA represents the purest language that caries literary heritage accompanied with a glorious reservoir of vocabulary whereas MSA is quite different in style and lexicon. It is merely less complex in both oral and written modes.

3.4 Colloquial/Dialectal Arabic: (CoA) refers to those national, local or regional dialects for everyday conversations.i.e. 'ämmiyya or därijais widely used in informal contexts. The spoken variety is a mother tongue of a great number of Arab people. It is the variety that carries a series of fluxes in its system not solely on a national level but also at a regional one. The latter is usually named as "regional dialects". Fergusson posits that the use of L or H away from their real contexts can be definitely perceived as a violation to sociolinguistic norms of Diglossia.

\section{Arabization as a Language Policy}

It is erroneous to most of the time prioritize a language at the expense of another especially when it comes to a native language. There is a pertinent reality about Arabic that is traced back to the appearance of Islam in the Arab world. Arabization lies at the heart of language reforms that aim at protecting its status from any kind of alteration. Arabic is also a language of instruction in the sphere of education. 
In doing so, it is hard to reshape its linguistic reality as far as emotive beliefs are linked to it. However, Arabization that aims at sketching the contours to deeps its root within the educational system, attempts to bring utilitarian value as a response to the negligence that it has been exposed to.

At a general glance, the linguistic hegemony of world powerful languages such as: French and English widens the gap between Arabic and these developed languages. It is not surprising that neo-colonialism tries hardly to oust local languages as they said to be incompetent to absorb better socioeconomic situations. The Arabic language is poorly researched in spite of the fact that, considerable efforts have been made by scholars and Arabization organizations alike.

Upon seeing the effect of language contact in Arab societies, there is a common belief that ex-colonial languages aim at marginalizing Arabic although it holds the status of both official and national language. As far as the case of Algeria is concerned, there is a strong attitude that favours Arabic due to the Arab nationalism. The absence of unification between Arab countries and the stagnation stands as an obstacle against a clear methodology to attain quality-based education and socioeconomic opportunities.

Arabization in Algeria aimed to -behind the process of identity 'embedding'- ground that sentiment of fossilizing Arabic within the sociolinguistic reality of the nation. Yet, the hindrance that stands against the use of SA is not solely envisaged through ideology; on the contrary, linguistic incompetence in MSA is therefore popular among Algerians themselves. (Grandguillaume, 1996, p.13) contends that 'nul de conteste que l'arabe soit la langue nationale mais peu d'algériens manifestent cet arabe classique tant que à l'oral qui à l'écrit'. ${ }^{2}$

While the national and official languages in Algeria are both Arabic and Berber, Algerian Arabic (AA) is thus, the mother tongue of a huge number of the Algerian population. Since dialects are not "codified" (Stewart ,1968,p.536) it is not logical to mention that the political importance of a language was given to Arabic by chance, at the same vein; it is noteworthy to mention that Berber has not been standardized yet despite its status as an official language.

The language policy in Algeria has aimed at rooting Arabic within the Algerian sociolinguistic frame since "Arabic's special status as the language in which Allah's message was revealed to Muhammad made it unassailable". (Weitzman, 2012, p110). Moving back to authenticity has been of a great importance. However, the results have been turned backwards in favor to French. (Weinstein, 1990, p.14) maintains that:

Language policy and planning can assist efforts to change the state and society in radical ways: changing identities, replacing one elite by another in the state apparatus, and altering patterns of access to reflect the replacement of a dominant class or ethnic group.

\section{Bilingualism in Regards to CA}

The linguistic case of the Arab world is framed as being exemplary through the existence of more than one language. Beside Arabic, both former colonial languages such as French and English have extensively dominated fields of science and technology. As such, administration and business are nowadays heavily dependent on these languages, especially English at a greater extent. In an attempt, the phenomenon of bilingualism enforces the emergence of two distinct varieties of two genetically unrelated languages. The initial framework of Diglossia in the Arab world is indeed changed according to historical, economic and strategic reasons whereby Arab citizens find themselves shifting between two linguistic codes to meet certain communicative aims.

Bilingualism is no more tinged with ideological attitudes on the contrary; instrumental motives have led Arab speakers to shift their language use to another and vice versa. As a matter of fact, Arab speakers are likely enthusiastic towards foreign languages. They believe that they can open new horizons for better job opportunities be it in their home lands or even abroad. However, aside from the advantages of bilingualism, there may be hindsight about the negative effects of foreign languages hegemony on the Arab world. CA can expectedly face a traumatic negligence especially by the pros elites who still hold positive attitudes towards the usefulness of the ex-colonial languages. These languages possess a higher degree of privilege and in parallel; they are acquired -in many cases- as a mother tongue instead of Arabic.

\footnotetext{
${ }^{2}$ Author's translation: 'No one can deny that Arabic is the 'national language' but only few Algerians are able to speak and write in classical Arabic."
} 
The language contact situation in Algeria is an interesting case that merits closer analysis. Algeria is definitely a multilingual society by the existence of three languages mainly: Arabic, Berber and French ${ }^{3}$. After the departure of the French colonizer, the country has found itself reconstructing the bedrocks of its identity and culture. The only solution for policy makers was to promote the ritual language of Quran, i.e. Arabic, as the only language of the young independent republic in order to drop away French linguistic assimilation. From 1962 onwards, Arabic is the national and official language of Algeria as clearly stated in the Algerian constitution.

\subsection{Borrowing in the Algerian Context: French Loanwords}

From a linguistic perspective, language contact in a given society holds strong outcomes that can be well noticed through the changes associated to a language or variety of language. In the current globalized world, languages undergo an alteration in their linguistic system as a way of reaching simplicity to fit informal interactions. Borrowing for instance, is one of the widely spread sociolinguistic phenomena especially in Algeria. It is noteworthy to mention some examples as shown in the table below:

\begin{tabular}{|l|l|l|}
\hline Borrowed words & Words origin & Equivalent in English \\
\hline$[$ Ta:bla] & Table & Table \\
\hline [grafata] & Graffate & Tie \\
\hline [Likoul] & Ecole & school \\
\hline [nKonakti] & Connecter & Connect \\
\hline
\end{tabular}

\subsection{Some Borrowed French Words}

Borrowing has been integrated within everyday conversations of Algerian dialectal Arabic. One might question whether it can be brought in line with linguistic evolution to meet communicative needs or simply a way to decrease linguistic handicap. While languages are seen to be a purely human activity, the spread of French comes from its functions as the language of trade, business and even educational and cultural transactions that exist between the two countries. More importantly, French remain -par excellence- the language of instruction for scientific and technical fields at the university level.

The adaptation of the ex -colonial loan words cannot be avoided as a consequence to the imposition of French for more than centuries in addition to the geographical position of both countries that is one of the mere factors of such influence. It would not be a mistake if we consider bilingualism as a norm rather than an exception. Re-shaping the linguistic reality requires constant planning and a logical match between theory and practice

The educated segment of the Algerian society is at least bilingual, not only by chance, but merely by linguistic heterogeneity that is rightly or wrongly becomes a part of the language profile of Algeria. Currently, Berber ${ }^{4}$, the Afroasiatic language is institutionalized as an official language beside Arabic. This spoken variety has not yet undergone through a codified system.

In addition to the Arab world, the Algerian population speaks a variety of dialects ranging between Algerian Arabic and Berber. The dialect (henceforth AA) is supposed to lack a prestigious value since it has no written system. In this retrospect, calls have risen in the Arab world in order to institutionalize and standardize these local dialects or vernaculars into standardized languages. As for the case of Berber in Algeria, agreement about the choice of writing script still causes controversy. As far as the Arabic Maghreb dialect is concerned, it is characterized by the stress shift in its phonological system for example: žbal<jabal'mountain. In addition to $\mathrm{CvCC}$ syllable structure as in:qabr>qbar' grave'; saqf>sqaf' roof'. (Cited in Versteegh, 2014, p.213)

\section{Arabic as a World Empowering Language: Hidden Potentials}

A number of claims in the Arab world favor multilingualism to Arabic. This is due to the attitudes that people hold towards it. It is wrong to assume that language is responsible upon the failure of its speakers. Indeed, (Crystal, 2003) emphasizes the reason behind the triumph of Latin as an international language. He mentions that romans were powerful so their strength had an enormous impact on the whole world.

Crystal strongly advocates that the spread of any given language equals the advancement of its speakers rather than the number of its population; above all, 'when they fail, their language fails'.(ibid,p.7)

\footnotetext{
${ }^{3}$ There is no mention to English since it has not yet reached a social function in Algeria.

${ }^{4}$ Berber has gained the status of an official language in 2016 (see the: conseil-constitutionnel.dz/index.php/fr/) 
It is important to elevate the debate about language issue in the Arab world from the perspective of absolute nationalism that ascertains identical connection to Arabic.

There is share of positive attitudes towards rejecting the idea of substituting Arabic by any other world language for the sake of reaching modernization. To be reasonable, the attitudes that exist towards Arabic may also generate opponents who still believe that language is unable thereby to fulfill fervent wishes for a better future. The bone of contention proves that policy makers still, till now could not speed the process by which Arabic can manifest and carry knowledge and modern sciences. In contrast, advocates believe strongly in Arabic because it is the 'language of Islam's holy book, the Koran, and is such a religious and liturgical of all Muslims regardless of origin.' (Holes, 2004, p. I)

The case of Arab countries is theoretically similar. The status of Arabic eliminates any language barrier that may appear amongst Arab people while at the same time, this reality would stand along the lines of unity and collaboration which has not yet reached sufficiency because of some political orientations. The Arabic language, as any other world language, is able to regain its glorious past but only if policy makers can kindle interest in how to modernize Arabic instead of keeping it limited to identity and religion. A systematic approach to Arabization should be double checked. Organizations and committees should work deeply on both corpus and acquisition planning. Governments need to pay sizable efforts in order to promote Arabic since the current globalized world forces nations to adopt the western model of politics, culture and economy. (Suleiman, 2003, p.13) affirms that:

The general trend in Arab nationalist thought is to treat Arabic as the marker of the Arab national identity and as a medium of modernization which, in itself, is in need of modernization to enable it to become the communicative instrument of a flourishing and nationally conscious Arab life in the modern period.

The language issue is nevertheless murky and raises questions of planning and attitudes. The Algerian case has shown the standing of two types of elites. The former denotes Arabization proponents who strongly consider Arabic proudly with a linkage to nationalism and belonging to the Arab world. On the other part, those opponent francophone elites defend the superiority of French over the world of economy and science. There is a widening gap between Arabic and French because the job market is controlled by the French language.

Needless to say, the decline of a vivid language is regrettable. Arabic has not taken its share from competent and professional linguists. As we said previously, reforms need to be tackled. Hesitations towards Arabic should be abolished. To suit the modern time, rapid implementation of Arabization for instance is never supposed to be a on the top list of political agenda, hence, financial support along logical planning would lead Arabic to a safer position. Yet, further arguments prove in a way or another treasury resource of labels existing within Arabic lexicon.

As mentioned earlier, the world today is waking up to new realities whereby some languages are rewarded the position of "international language" whereas others still resist despite invested efforts to promote their positions. Even so, the fallacy is when we underestimate the value of a local language. Within the same vain, (Halliday, 1972) stresses the fact that all languages share an equal level of importance and hence the concept of 'under developed' language has no credibility. To keep a language alive, a TV programme can itself succeed in encouraging the audience to be receptive to the content displayed and then stimulate the desire to debate in response to what has been introduced. This is positive reinforcement to "language exposition" that may be advantageous for a long term. While foreign languages are the vehicle of information reception, local languages are undoubtedly the means of sovereignty and pride.

The Arabic language denotes a solid sense of unification to the Arab world. Therefore, the standard variety proves rigorously to grammarians, linguists and even politicians that it carries a magnificent aspect of fancy stylistic meaning, any other developed language in a sense can be powerful because of deliberate technological and scientific revolution, but it may lose evidently in front of the power of language interpretation and complex grammar of CA.

The diglossic situation that is drawn to Arabic is not necessarily resilient. The standard variety of Arabic accumulates the divergent reality under the umbrella of 'AL wihda Al wataniya'. Though, the existing dialects are not supposed to be marginalized, their dialectal features show cultural and ethnic mosaic which bring together the feeling of distinctiveness.

The codification of dialects can be a double edged sword. The current linguistic reality of the Arab world suffers deeply from a dis-unification trauma in various domains. Although, there is one shared language, the political reality remains unsatisfactory. Whatever the reasons, division is what characterizes the unfortunate case of Arabs. For both panArabism and pan- Islamism, the replacement of Arab by any indigenous or even CoA is not tolerated. Calls for standardization of dialects come mostly from those non- Muslim intellectuals who do not own any sentimental connection to Arabic as the tongue of Islam. 


\section{Arabic within the Framework of Globalization: Implications}

The revival of Arabic has become a heightened value in order to ensure the criterion of "democracy" throughout the Arab land. Globalization, today, entails new orders and principles about how the new mold of life is pictured in terms of effective educational and economic institutions. (Taha-Thomure, 2008, p.5) Explains that:

Having institutional funding will undoubtedly create a buzz that will make establishing quality teacher training programs possible and would make developing effective curricula, standards and instructional materials needed in the Arabic language classroom a reality.

Building upon this quotation, the Arabic language needs solidarity which can be voiced solely by its speakers. Yet, one political order should go hand in hand with a revolutionary and strategic reform to exclude the fact of sidelining Arabic away from the educational system. There are estimably around 256 million speaker of Arabic. This demographic number will knock the alarm to integrate the human capital within the process of "Arabic modernization".

\section{Conclusion}

In a nutshell, language contact in the Arab world results from various factors, above the list, globalization and neocolonialism are the main ones. The Arabic language is a linguistic reality that cannot be given a second thought. One might add that, language policy and planning should undergo a practical approach of implementation to reach efficiency. As Algeria is a part of the Arab zone, any reform would surely affect it.

\section{References}

Crystal, D. (2003). English as a Global Language (2nd Ed.). Cambridge: Cambridge University

Ferguson, C. 1959. "Diglossia.” Word 15: 325-40. DOI: 10.1080/00437956.1959.11659702

Fishman, J.A (1967). Bilingualism with and without Diglossia; Diglossia with and without Bilingualism, Journal of Social Issues, 32, 29-38

Granguillaume, G. (1996). L'Algérie confrontée à L'Islamisme, in Le Monde Diplomatique. Edition Février 2000.

Halliday, M. A. K. (1972). National Language and Language Planning in a Multilingual

Society. East Africa Journal 9 (8), 4-13.

Holes, C. (2004), Modern Arabic: Structures, functions, and varieties, Washington, DC: Georgetown University Press.

Kaye, A. S. (2002). Comment. International Journal of the Sociology of Language, 157, 117-125.

Marçais, W. (1930) "La Diglossie”. In L’enseignement Public. No12. Paris: Delagrave. PP. 401-9

Maddy-Weitzman, Bruce.(2012) "Arabization and its Discontents: The Rise of the Amazigh Movement in North Africa." Journal of the Middle East and Africa 3, no. 2: 109-135.

Maamouri, M. (1998). Arabic Diglossia and its impact on the quality of Education in the

Arab Region. Philadelphia: International Literacy Institute.

Palmer, J. (2008). Arabic Diglossia: Student Perceptions of Spoken Arabic after Living in the Arabic-Speaking World. Arizona Working Papers in SLA \& Teaching, 15, 81-95. Retrieved

Stewart, W. A. (1968) .A Sociolinguistic Typology for Describing National Multilingualism.In Fishman, J.A (Ed).Readings in the Sociology of Language. Mouton Publishers, The Hague

Suleiman, y. (2003) the Arabic Language and National identity, Edinburg University Press.

Taha-Thomure, H. (2008). The Status of Arabic Language Teaching Today. Education, Business and Society: Contemporary Middle Eastern Issues, 1(3), 186-192, Emerald Group Publishing, Limited.

Versteegh, K. (2014). The Arabic Language. Edinburgh: Edinburgh University Press. 2nd Ed

Weinstein, B. (1990) Language Policy and Political Development: Ablex Publishing Corporation

Zughoul, M. R. (1980). Diglossia in Arabic: Investigating Solutions. Anthropological Linguistics, 22, 201-217 